See discussions, stats, and author profiles for this publication at: https://www.researchgate.net/publication/272846731

\title{
Effect of different lignocellulosic fibres on poly( $\varepsilon$-caprolactone)-based composites for potential applications in orthotics
}

Article in RSC Advances · February 2015

DOI: 10.1039/C5RA00832H

\section{CITATIONS}

17

8 authors, including:

Fabrizio Sarasini

Sapienza University of Rome

178 PUBLICATIONS 2,701 CITATIONS

SEE PROFILE

(बe) Debora Puglia

Università degli Studi di Perugia

206 PUBLICATIONS 4,448 CITATIONS

SEE PROFILE

Some of the authors of this publication are also working on these related projects:

Polymer composites and nanocomposites View project

Biopolymeric films View project
240

Jacopo Tirillò

Sapienza University of Rome

109 PUBLICATIONS 1,350 CITATIONS

SEE PROFILE

Jose M. Kenny

Università degli Studi di Perugia

751 PUBLICATIONS 21,059 CITATIONS

SEE PROFILE 


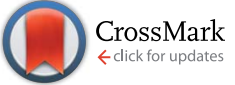

Cite this: RSC Adv., 2015, 5, 23798
Received 14th January 2015 Accepted 26th February 2015

DOI: $10.1039 / \mathrm{c} 5 \mathrm{ra} 00832 \mathrm{~h}$

www.rsc.org/advances

\section{Effect of different lignocellulosic fibres on poly ( $\varepsilon$-caprolactone)-based composites for potential applications in orthotics $\uparrow$}

\author{
Fabrizio Sarasini, ${ }^{\text {a }}$ Jacopo Tirillò, ${ }^{a}$ Debora Puglia, ${ }^{\mathrm{b}}$ José M. Kenny, ${ }^{\mathrm{b}}$ Franco Dominici, ${ }^{\mathrm{b}}$ \\ Carlo Santulli, ${ }^{c}$ Marco Tofani ${ }^{\mathrm{d}}$ and Rita De Santis ${ }^{\mathrm{d}}$
}

\begin{abstract}
This work compares the mechanical and thermal behaviour of fully biodegradable biocomposites based on polycaprolactone reinforced with three different natural fibres, namely hemp, sisal and coir, for potential applications in the field of orthoses. The same properties were further compared to those of two commercially available materials commonly used in the same prospective field. The results confirmed that the addition of natural fibres, irrespective of the origin of the fibres (leaf, bast or fruit) to a biodegradable matrix allows for significant improvement of the mechanical behaviour of the ensuing composites compared to traditional thermoplastic materials used in orthotics.
\end{abstract}

\section{Introduction}

Derived from the Greek word "orthos" that means "straight", orthoses have been used for thousands of years. ${ }^{1}$ An orthotic device is designed for the support of weak or ineffective joints or muscles whereas orthotics is usually defined as "a branch of mechanical and medical science dealing with the support and bracing of weak or ineffective joints or muscles" ${ }^{2}$ and currently three terms are often used interchangeably, namely splint, brace, and orthosis, while support is considered a synonym for all three terms. Orthoses can serve multiple functions, including controlling, correcting, facilitating, limiting, or inhibiting motion of the extremities or spine. Due to this variety of functions, it is common to refer to different types of splints, namely static, serial static, static progressive and dynamic (to correct deformity or to enable protected movement). ${ }^{3}$ Metals and plastics are the most common materials in modern orthotics. Material selection is strictly dependent on the function to be performed by the orthosis and the most important material characteristics comprehend strength, stiffness, durability, weight, corrosion resistance and the easiness of manufacturing and using them. Interestingly, while materials

\footnotetext{
${ }^{a}$ Sapienza-Università di Roma, Department of Chemical Engineering Materials Environment, UdR INSTM, via Eudossiana 18, 00184 Roma, Italy. E-mail: fabrizio. sarasini@uniroma1.it; Fax: +39 066876343; Tel: +390644585408

${ }^{b}$ Università di Perugia, Department of Civil and Environmental Engineering, UdR INSTM, Strada di Pentima 4, 05100 Terni, Italy

'Università degli Studi di Camerino, School of Architecture and Design (SAD), Viale della Rimembranza, 63100 Ascoli Piceno, Italy

${ }^{d}$ Sapienza-Università di Roma, Department of Anatomical, Histological, Forensic \& Orthopaedic Sciences, P.le A. Moro 5, 00185 Roma, Italy

$\dagger$ Electronic supplementary information (ESI) available. See DOI: $10.1039 / \mathrm{c} 5 \mathrm{ra00832h}$
}

changed dramatically especially during the $20^{\text {th }}$ century, the underlying design concepts were virtually unaffected by these modifications. Steel, aluminium and titanium alloys are the metals most commonly used in the fabrication of orthoses, even though one of the major breakthroughs was the introduction of thermoplastics in the 1970s, which improved cosmesis and circumferential control, because of their greater adaptability to complex anatomical shapes. Both petroleum-based thermoplastics and thermosets are used in the orthotics field, although thermoplastics are more common for custom-fabricated orthoses. Low-melting temperature thermoplastics become workable at temperatures in the range of 60 and $80{ }^{\circ} \mathrm{C}$ and can be formed directly on body segments, which can significantly reduce the time and cost involved in fabricating an orthosis. Over the last few years, the depletion of petroleum resources coupled with the adoption of stricter environmental regulations have stimulated the search for alternative materials and products with the lowest possible environmental 'footprint', with a focus on renewable raw materials that can be processed with lower energy consumption requirements, as found within the class of natural fibre composites (NFCs)., ${ }^{\mathbf{4} 5}$ Natural fibre composites are being considered as a possible replacement for synthetic composites (mainly glass fibre reinforced composites) in non structural or semi-structural applications. The last trend in biocomposites is represented by the replacement of petroleum-based polymers with the ones obtained from renewable resources, thus providing the so called green composites. $^{6}$

In this framework, the present experimental work aims to establish a new model for the design of splints or supports offering adequate trade-offs of economical and environmental aspects without compromising the effectiveness of the product for the patient's health. In detail, this work sets out both the 
possibility of using natural fibres as the reinforcement of a petroleum-based bioplastic, namely polycaprolactone (PCL), for the production of composites with lower environmental impact to be used in orthotics and the comparison of the mechanical properties of these new biocomposites with those of commercially available materials used in the same field. Splinting materials based on polycaprolactones were first introduced in the mid to late 1970s and the first of these new materials, Polyform and Aquaplast, were instant successes. ${ }^{2}$ As regards PCL, different types of cellulose-based natural fibres have been successfully incorporated as fillers to obtain biodegradable composites with improved properties. Table 1S (ESI $\dagger$ ) presents a survey of studies available in literature related to the use of PCL as matrix for natural fibre composites. Available studies suggest that sisal fibres are the most investigated among the lignocellulosic ones, with very few studies dealing with hemp fibres. In literature, to the best of authors' knowledge, there is no study comparing the effect of different lignocellulosic fillers on the final mechanical and thermal performance of PCL-based composites manufactured in the same experimental conditions. In this regard, the aim of the present study is to prepare biocomposites based on polycaprolactone reinforced with fillers extracted from different parts of plants, namely bast (hemp), leaf (sisal) and fruit (coir) and to compare their reinforcing efficiency with a view to having a material suitable for orthotic devices with a lower environmental impact and potentially improved strength and fatigue resistance over traditional thermoplastics used in orthotics. The over-dependence on petroleum resources is meant to be overcome through the replacement of some polymer with fibres from renewable resources.

\section{Experimental}

\section{Materials}

Polycaprolactone Capa ${ }^{\mathrm{TM}} 6500\left(M_{\mathrm{n}}=50000 \mathrm{~g} \mathrm{~mol}^{-1}, T_{\mathrm{m}}=58-\right.$ $\left.\left.60{ }^{\circ} \mathrm{C}, \mathrm{MFI}_{(2.16 \mathrm{~kg} / 160}{ }^{\circ} \mathrm{C}\right)=7.90 \mathrm{~g} / 10 \mathrm{~min}\right)$, supplied by Perstorp, was used as matrix. Three different natural fibres were used as reinforcement, namely sisal (Agave sisalana) (S), coir (Cocos nucifera) (C) and hemp (Cannabis sativa) $(\mathrm{H})$. The fibres were not subject to any surface chemical treatment to improve adhesion with polymer matrix and were dried at $98{ }^{\circ} \mathrm{C}$ in a vacuum oven for $24 \mathrm{~h}$, prior to the preparation of the composites. As a reference, two commercial products commonly used in orthotics were tested, namely Orfit ${ }^{\circledR}$ Eco Nat $2.4 \mathrm{~mm}$ by Orfit Industries e Rolyan ${ }^{\circledR}$ Aquaplast ${ }^{\circledR}$ ProDrape-T by Patterson Medical Holdings, Inc.

\section{Compounding and processing}

PCL pellets were dried in a vacuum oven at $30{ }^{\circ} \mathrm{C}$ for $24 \mathrm{~h}$ before compounding. The PCL composites were manufactured using a twin-screw microextruder (Explore 5\&15 CC Micro Compounder by DSM) and mixing process parameters (50 rpm screw speed, 2 min mixing time, and temperature profile: $60-75-90{ }^{\circ} \mathrm{C}$ ) were modulated to optimize final material properties. To obtain the desired specimens for characterization, the molten composite samples were transferred, after extrusion, through a preheated cylinder to a mini-injection mould $\left(T_{\text {mold }}=25{ }^{\circ} \mathrm{C}, T_{\text {injection }}=\right.$ $90{ }^{\circ} \mathrm{C}$ ) with the following pressure cycle: $P_{\text {injection }}=2$ bar (hold time $=4 \mathrm{~s}$ ), 3 bar (hold time $=6 \mathrm{~s}$ ) and 3 bar (hold time $=12 \mathrm{~s}$ ). Composites with different amount of natural fibres were fabricated: initially, a masterbatch containing $30 \mathrm{wt} \%$ of each natural fibre was prepared, while the other compositions (10 and $20 \mathrm{wt} \%$ ) were obtained by diluting the master with neat PCL.

\section{Characterization}

Single fibre tensile tests. As the mechanical properties of composites are strongly influenced by the properties of the reinforcement used, each natural fibre type was tested in tension. This analysis was deemed necessary to compare the properties of composites without using literature data that are not usually obtained in the same testing conditions. Single-fibre tensile properties were determined following the method described in ASTM C1557-03. Single fibres were carefully separated from the fibre bundles by hand. Tensile tests were carried out at room temperature by means of a Zwick/Roell Z010 equipped with a 200 $\mathrm{N}$ load cell. Three different gauge lengths were tested, namely 20 , 30 , and $40 \mathrm{~mm}$. Individual fibres were glued onto card tabs with a central window cut out to match the desired gauge length for the test. Tests were performed in displacement control at a crosshead speed of $1 \mathrm{~mm} \mathrm{~min}^{-1}$. For each gauge length and type of natural fibre, twenty fibres were tested. Fibre diameter was evaluated through optical observations (Nikon Eclipse 150L) as the average of five apparent diameter measurements taken at different locations along the fibre: this was deemed sufficient, since only fibres with reduced diameter variability were carefully selected for testing. The apparent cross-sectional area of each fibre was then calculated from the mean fibre diameter assuming a circular cross-section..$^{7-11}$ To calculate the Young's modulus of a single fibre using tensile test data, it was necessary to obtain accurate values for tensile load and displacement (elongation). Unfortunately, the use of standard extensometers and strain gauges on single fibres is not possible due to the small diameters of the fibres. The fibre displacement experienced during tensile testing can therefore only be measured from the displacement of the testing machine crosshead. The cross-head displacement, however, is actually a combination of the fibre elongation as well as the crosshead deformation, specimen grips, and the cardboard mounting card. The actual specimen elongation in the gauge length can be determined by subtracting the displacement associated with the system compliance from the total cross-head displacement. The system compliance was determined according to ASTM C1557 for the given test machine, gripping system and type of fibre by obtaining the force versus displacement behaviour of the fibres at three gauge lengths (ten tests at each gauge length $\left.\left(l_{0}\right)\right)$. The cross-head displacement during fibre testing, $\Delta L$, can be expressed by:

$$
\frac{\Delta L}{F}=l_{0}\left[\frac{1}{E A}\right]+C_{\mathrm{s}}
$$

where $C_{\mathrm{s}}$ is the machine compliance, $F$ is the applied force, $E$ is the Young's modulus of the fibre, and $A$ is the cross-sectional 
Table 1 Comparison between mechanical results obtained in this work and data available from open literature for coir fibres

\begin{tabular}{|c|c|c|c|c|c|c|}
\hline $\begin{array}{l}\text { Gauge length } \\
(\mathrm{mm})\end{array}$ & $\begin{array}{l}\text { Average diameter } \\
(\mu \mathrm{m})\end{array}$ & $\begin{array}{l}\text { Tensile strength } \\
\text { (MPa) }\end{array}$ & $\begin{array}{l}\text { Young's modulus } \\
\text { (GPa) }\end{array}$ & $\begin{array}{l}\text { Strain-to-failure } \\
(\%)\end{array}$ & Weibull modulus & References \\
\hline 5 & $198 \pm 75$ & $162 \pm 32-192 \pm 37^{c}$ & 3.44 & $26.1 \pm 5.6-42.4 \pm 14.0^{c}$ & 6.0 & $21^{a}$ \\
\hline 15 & & & & & 5.8 & \\
\hline 25 & & & & & 6.0 & \\
\hline 30 & & & & & 6.0 & \\
\hline 10 & & & & & - & \\
\hline 15 & & & & & 9.3 & \\
\hline 25 & & & & & 5.5 & \\
\hline 30 & & & & & - & \\
\hline 35 & & & & & 3.7 & \\
\hline 50 & $335.4 \pm 61.2$ & $76 \pm 15$ & $2.1 \pm 0.3$ & $29 \pm 5$ & - & 25 \\
\hline 50 & & $243 \pm 83$ & $6.0 \pm 1.8$ & $22 \pm 7$ & & \\
\hline 100 & & $201 \pm 73$ & $4.6 \pm 1.4$ & $20 \pm 9$ & & \\
\hline 5 & 225 & $142.6 \pm 53.26$ & $1.27 \pm 0.39$ & $59.87 \pm 23.80$ & - & 22 \\
\hline 10 & & $135.4 \pm 44.8$ & $1.97 \pm 0.39$ & $34.04 \pm 15.86$ & & \\
\hline 20 & & $128.7 \pm 47.4$ & $2.30 \pm 0.71$ & $29.91 \pm 12.09$ & & \\
\hline 25 & & $118.3 \pm 35.56$ & $2.73 \pm 0.91$ & $25.01 \pm 12.50$ & & \\
\hline- & - & 117.5 & 0.628 & 14.8 & - & 27 \\
\hline 20 & $227.31 \pm 107.55$ & $108.66 \pm 40.28$ & $3.80 \pm 1.77$ & $15.90 \pm 5.00$ & See Table 4 & This work \\
\hline 30 & & $100.37 \pm 40.66$ & $3.69 \pm 1.47$ & $20.07 \pm 10.16$ & & \\
\hline 40 & & $98.97 \pm 32.51$ & $3.53 \pm 1.01$ & $15.98 \pm 6.64$ & & \\
\hline
\end{tabular}

${ }^{a}$ White coir. ${ }^{b}$ Brown coir. ${ }^{c}$ Weakest test length-strongest test length. ${ }^{d}$ Data from six different coir varieties (long fibres, arbitrarily chosen $>12.7$ $\mathrm{cm}$ ). ${ }^{e}$ Data from six different coir varieties (short fibres, arbitrarily chosen $<12.7 \mathrm{~cm}$ ). ${ }^{f}$ Retted high quality coir fibres (Anjengo).

area of the fibre. Therefore a plot of $(\Delta L / F)$ versus gauge length, $\left(l_{0}\right)$, will yield a straight line of slope $1 /(E A)$ and intercept $C_{\mathrm{s}}$, the compliance of the load train. The actual elongation of the gauge section of the specimen is as follows:

$$
\Delta l=\Delta L-C_{\mathrm{s}} F
$$

The evaluated testing device compliance was, in the present case, quite small $\left(0.027,0.028\right.$ and $0.011 \mathrm{~mm} \mathrm{~N}^{-1}$ for coir, hemp and sisal fibres, respectively).
The scatter of the Young's modulus and tensile strength was statistically analysed using a two-parameter Weibull distribution, according to the following expression:

$$
F(\chi)=\exp \left[-\left(\frac{\chi}{\chi_{0}}\right)^{\alpha}\right]
$$

where $F(\chi)$ is the probability of survival of the parameter $\chi, \alpha$ is a dimensionless shape parameter (related to the dispersion of the data) and $\chi_{0}$ is a scale parameter. The probability of failure was estimated by the median rank value:

\begin{tabular}{|c|c|c|c|c|c|c|}
\hline $\begin{array}{l}\text { Gauge length } \\
(\mathrm{mm})\end{array}$ & $\begin{array}{l}\text { Average diameter } \\
(\mu \mathrm{m})\end{array}$ & $\begin{array}{l}\text { Tensile strength } \\
(\mathrm{MPa})\end{array}$ & $\begin{array}{l}\text { Young's modulus } \\
(\mathrm{GPa})\end{array}$ & $\begin{array}{l}\text { Strain-to-failure } \\
(\%)\end{array}$ & Weibull modulus & References \\
\hline 10 & 42 & $285(168-480)^{a}$ & $14.4(5.6-30.1)^{a}$ & $2.2(1.3-3.3)^{a}$ & 2.86 & 28 \\
\hline 10 & $26.5 \pm 6.7$ & $514 \pm 274$ & $24.8 \pm 16.3$ & - & - & 29 \\
\hline 20 & $10.86 \pm 1.6$ & $2140 \pm 504$ & $143.2 \pm 26.7$ & $1.8 \pm 0.7$ & 4.6 & 30 \\
\hline 11 & $67 \pm 26$ & $277 \pm 191$ & $9.5 \pm 5.7$ & $2.3 \pm 0.8$ & - & 31 \\
\hline - & $31.2 \pm 4.9$ & $270 \pm 0.04$ & $19.1 \pm 4.30$ & $0.80 \pm 0.10$ & - & 32 \\
\hline 10 & $31.5 \pm 7.3$ & $577 \pm 70$ & $26.5 \pm 6$ & $1-2$ & - & 33 \\
\hline 10 & $17.66 \pm 7.59$ & $788 \pm 307$ & $44.52 \pm 19.1$ & $1.8 \pm 0.69$ & - & 17 \\
\hline 20 & $125.51 \pm 53.72$ & $350.94 \pm 147.46$ & $51.33 \pm 20.91$ & $0.99 \pm 0.38$ & See Table 4 & This work \\
\hline 30 & & $301.05 \pm 163.47$ & $43.65 \pm 15.60$ & $0.91 \pm 0.34$ & & \\
\hline 40 & & $224.52 \pm 86.18$ & $34.89 \pm 13.86$ & $0.88 \pm 0.30$ & & \\
\hline
\end{tabular}

Table 2 Comparison between mechanical results obtained in this work and data available from open literature for hemp fibres 
Table 3 Comparison between mechanical results obtained in this work and data available from open literature for sisal fibres

\begin{tabular}{|c|c|c|c|c|c|c|}
\hline $\begin{array}{l}\text { Gauge length } \\
(\mathrm{mm})\end{array}$ & $\begin{array}{l}\text { Average diameter } \\
(\mu \mathrm{m})\end{array}$ & $\begin{array}{l}\text { Tensile strength } \\
\text { (MPa) }\end{array}$ & $\begin{array}{l}\text { Young's modulus } \\
\text { (GPa) }\end{array}$ & $\begin{array}{l}\text { Strain-to-failure } \\
(\%)\end{array}$ & Weibull modulus & References \\
\hline 10 & $-^{a}$ & $391 \pm 89$ & $17.7 \pm 9.4$ & $5.2 \pm 2.5$ & 4.6 & 15 \\
\hline 30 & $-^{c}$ & $385 \pm 99$ & $18.8 \pm 7.5$ & $2.8 \pm 0.6$ & 3.6 & \\
\hline 40 & $-^{d}$ & $400 \pm 126$ & $19.0 \pm 6.9$ & $2.6 \pm 0.8$ & 3.0 & \\
\hline 20 & $240 \pm 27$ & $462 \pm 71$ & $7.47 \pm 1.37$ & $7.83 \pm 1.25$ & - & 34 \\
\hline 30 & $200-400$ & $283.5 \pm 34.30$ & $5.24 \pm 0.86$ & $7.84 \pm 0.77$ & - & 36 \\
\hline 20 & $212.19 \pm 27.49$ & $365.64 \pm 97.44$ & $15.11 \pm 5.27$ & $2.98 \pm 0.56$ & See Table 4 & This work \\
\hline 30 & & $329.66 \pm 110.65$ & $11.72 \pm 5.73$ & $2.96 \pm 1.11$ & & \\
\hline 40 & & $271.74 \pm 148.25$ & $14.66 \pm 5.33$ & $2.60 \pm 0.45$ & & \\
\hline
\end{tabular}

${ }^{a}$ Fibre's cross section $=0.046 \pm 0.008 \mathrm{~mm}^{2} .{ }^{b}$ Fibre's cross section $=0.050 \pm 0.020 \mathrm{~mm}^{2} .{ }^{c}$ Fibre's cross section $=0.040 \pm 0.004 \mathrm{~mm}{ }^{2} .{ }^{d}$ Fibre's cross section $=0.046 \pm 0.013 \mathrm{~mm}^{2}$.

$$
F=\frac{i-0.3}{n+0.4}
$$

where $i$ is the rank of the $i$ th data point and $n$ is the number of data. A single set of parameters for each property (i.e. tensile strength and Young's modulus), $\chi_{0}$ and $\alpha$, which simultaneously fits all the data was obtained from the slope and intercept of the plot $\ln (-\ln (1-F))$ versus $\ln (\chi)$.

Mechanical properties of composites. Tensile tests were performed in displacement control using a crosshead speed of $5 \mathrm{~mm} \mathrm{~min}^{-1}$ and a load cell of $10 \mathrm{kN}$ by means of a Zwick/Roell Z010 testing machine, according to UNI EN ISO standard 5272. Type 1BA sample was used for tensile measurement, and for the evaluation of Young's modulus a contacting extensometer with a gauge length of $30 \mathrm{~mm}$ was used. The measurements were performed at room temperature and at least five samples were tested, expressing the results as mean value and standard deviation. Hardness measurements (Shore D) were performed according to ASTM D-2240, using an Instron Shore Model S1 Digital Durometer. The hardness value for each sample was calculated as the average of 30 measurements at room temperature. Similar tests have been carried out on samples of neat PCL and on two commercial products commonly used in orthotics, namely Orfit ${ }^{\circledR}$ Eco Nat e Rolyan ${ }^{\circledR}$ Aquaplast ${ }^{\circledR}$ ProDrape-T.

Differential scanning calorimetry (DSC). The melting and crystallization behaviour of the polymer matrix and the composites were studied in triplicate by using a TA DSC Q-200 instrument under inert $\mathrm{N}_{2}$ atmosphere. Specimens were subjected to the following thermal program: heating from $-90^{\circ} \mathrm{C}$ to $100{ }^{\circ} \mathrm{C}$ ( $3 \mathrm{~min}$ hold $)$, cooling to $-90^{\circ} \mathrm{C}$ ( $3 \mathrm{~min}$ hold $)$ and heating to $100{ }^{\circ} \mathrm{C}$, all steps at $10{ }^{\circ} \mathrm{C} \mathrm{min}^{-1}$. Peak temperatures for melting and crystallization were evaluated and the degree of crystallinity of the sample was calculated taking as reference 139.5 $\mathrm{J} \mathrm{g}^{-1}{ }^{12}$ as heat of melting of the fully crystalline PCL sample according to the eqn (5):

$$
X_{\mathrm{c}}=\frac{\Delta H_{\mathrm{m}}}{\Delta H_{\mathrm{m}}^{0}\left(1-w_{\text {fibre }}\right)} \times 100
$$

where: $\Delta H_{\mathrm{m}}=$ experimental enthalpy of melting of the sample $\left(\mathrm{J} \mathrm{g}^{-1}\right), \Delta H_{\mathrm{m}}^{0}=$ enthalpy of melting for $100 \%$ crystalline PCL $\left(\mathrm{J} \mathrm{g}^{-1}\right), w_{\text {fibre }}=$ weight fraction of natural fibres.

Morphological analysis. The fibre's microstructure and the morphology of composites' fractured surfaces were investigated by scanning electron microscopy (SEM) using a Philips XL40. All specimens were sputter coated with gold prior to examination.

\section{Results and discussion}

Natural fibres investigated in the present study showed the well known features already detailed in other studies. ${ }^{\mathbf{1 3 , 1 4}}$ For the sake of clarity, the morphology of all fibres is reported at different magnifications in Fig. 1S (ESI $\dagger$ ). The fibres exhibited quite dissimilar features with traditional pit-like openings on the surface of coir fibres (Fig. 1Sb $\dagger$ ), presence of polysaccharides residues detached from the otherwise quite smooth surface of hemp fibres (Fig. 1Sd $\dagger$ ), remains of polygonal-shaped parenchyma cells around sisal fibres (Fig. 1Sf $\dagger$ ). It is easy to recognize several elementary fibres (referred also to as ultimate fibres or cells) overlapped along the length of the fibres and bonded firmly together by pectin and other non-cellulosic compounds that give strength to the bundle as a whole.

\section{Tensile behaviour of hemp, coir and sisal fibres}

Single filament tensile test results of small brittle natural fibres are difficult to analyze due to the high scatter observed. This scatter can be mainly related to three factors, namely test parameters/conditions, plant characteristics and cross-section measurements. ${ }^{15}$ Both tensile strength and modulus were found to decrease with the increase of the diameter as commonly found in other studies on natural fibres. ${ }^{10,11,16-20} \mathrm{~A}$ wide range of diameters in the same bunch of fibres and a high dispersion of results were observed. All the related data are reported in Fig. 2-4S (ESI $\dagger$ ). The results for the average fibre strength and modulus of the natural fibres are summarized, as a function of the sample gauge length, in Tables 1-3. In spite of the differences in testing conditions, gauge length, fibre 


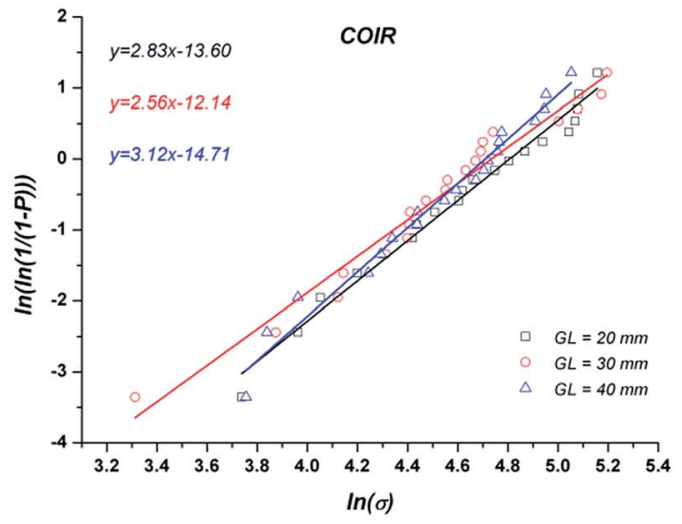

(a)

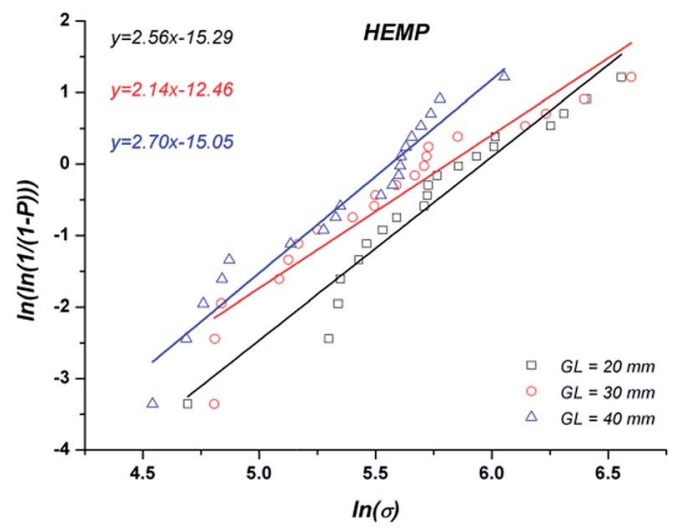

(c)

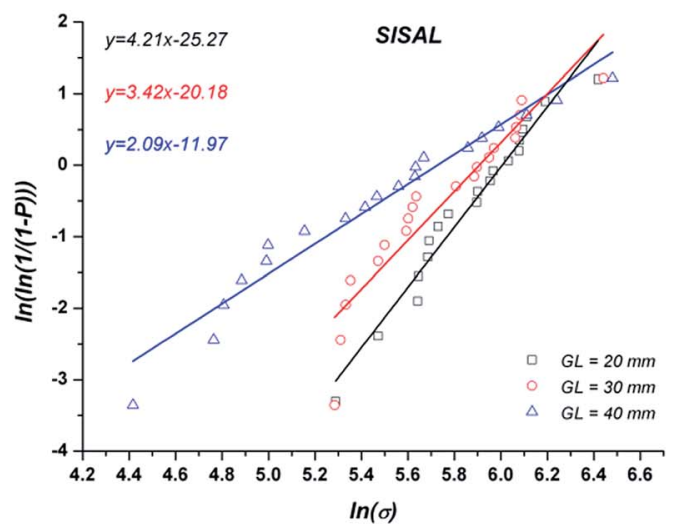

(e)

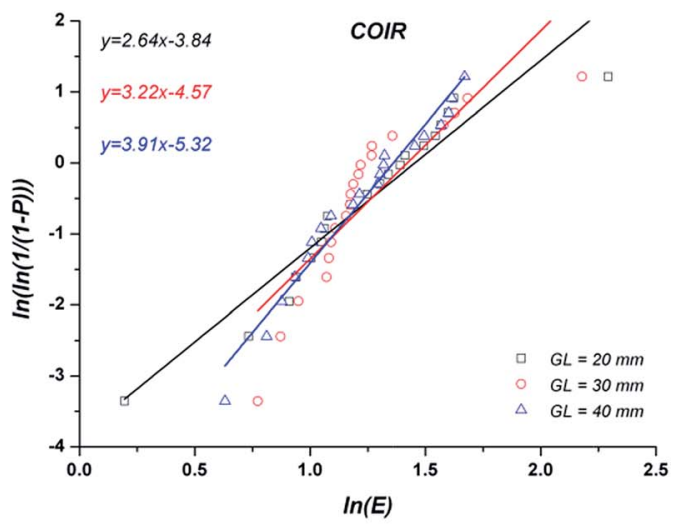

(b)

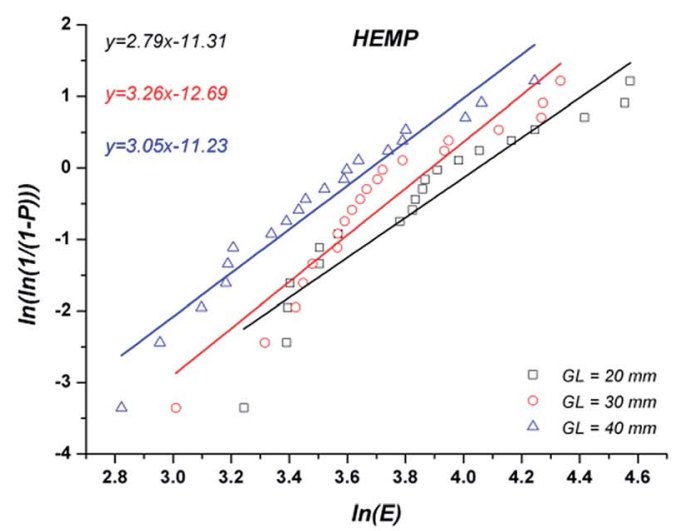

(d)

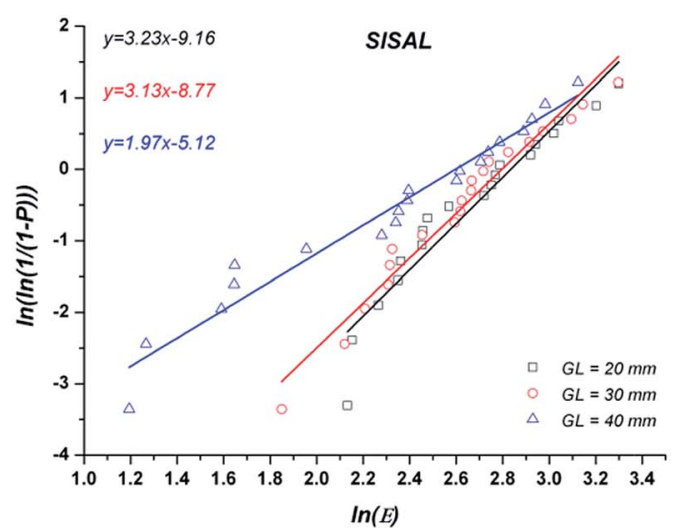

(f)

Fig. 1 Weibull plots for tensile strength and Young's modulus as a function of gauge length for (a-b) coir, (c-d) hemp and (e-f) sisal fibres.

extraction methods, degree of maturity of plants, the results of the present investigation compare quite well with the values reported in the literature. It can be also seen that tensile strength and Young's modulus are highly dependent on gauge length. At short gauge lengths the strength values are higher and decrease with increasing fibre length, as confirmed by other studies. ${ }^{\mathbf{1 0 , 1 1 , 2 1 - 2 4}}$ It was also found that the failure strain was less influenced by the increasing gauge length. This behaviour could be ascribed to the fact that final ductility is a complex combination of both mean defect size and number of defects, which is not easily determinable for natural fibres. In addition, natural fibres tend to show stress-strain curves that can vary from linear elastic to strain hardening behaviour, thus influencing the ensuing ductility, even within the same bunch of fibres. ${ }^{9}$ On the other hand, the dependence of failure strength on clamping length is a well-known characteristic of all fibres, which can be explained by the distribution of defects within the fibres. The longer the stressed length, the higher the number of defects present in the stressed fibre portion, contributing to the weakening of its structure. 
Table 4 Weibull parameters for coir, sisal and hemp fibres

\begin{tabular}{|c|c|c|c|c|c|}
\hline Natural fibre & $\begin{array}{l}\text { Gauge length } \\
(\mathrm{mm})\end{array}$ & $\begin{array}{l}\text { Tensile } \\
\text { strength }-\alpha\end{array}$ & $\begin{array}{l}\text { Tensile strength } \\
-\chi_{0}(\mathrm{MPa})\end{array}$ & $\begin{array}{l}\text { Young's } \\
\text { modulus }-\alpha\end{array}$ & $\begin{array}{l}\text { Young's } \\
\text { modulus - } \chi_{0}(\mathrm{GPa})\end{array}$ \\
\hline \multirow[t]{2}{*}{ Coir } & 20 & 2.83 & 122.30 & 2.64 & 4.28 \\
\hline & 40 & 3.12 & 110.98 & 3.91 & 3.90 \\
\hline \multirow[t]{2}{*}{ Sisal } & 20 & 4.21 & 405.56 & 17.02 & 3.23 \\
\hline & 30 & 3.42 & 367.55 & 16.38 & 3.13 \\
\hline & 30 & 2.14 & 333.55 & 3.26 & 48.80 \\
\hline & 40 & 2.70 & 260.75 & 3.05 & 39.69 \\
\hline
\end{tabular}

Quite contradictory results were obtained by Silva et $a l .{ }^{15}$ for sisal fibres, where neither tensile strength nor Young's modulus exhibited a dependence on gauge length in the range $10-40 \mathrm{~mm}$. The authors ascribed such behaviour to the fact that is the mean defect size to control the mean strength and this should not change with gauge length. Thus, they indicated the number of defects per unit length as the factor accounting for the influence of gauge length; in particular, it should control the Weibull modulus. They found that the Weibull modulus decreased from 4.6 to 3.0 when the gauge length was increased from $10 \mathrm{~mm}$ to $40 \mathrm{~mm}$, respectively. Also in the present study the differences in mechanical properties between natural fibres were analysed using a two-parameter Weibull distribution. The experimental fibre strength and Young's modulus distribution yielded by single fibre tests are shown in Weibull coordinates in Fig. 1, while the parameters of Weibull distribution are summarized in Table 4.

It is seen that the two-parameter Weibull distribution approximates reasonably well the experimental data at each gauge length. The Weibull plots obtained show a linear trend at each gauge length, thus implying that the failure of these natural fibres is dominated by a single-flaw population.

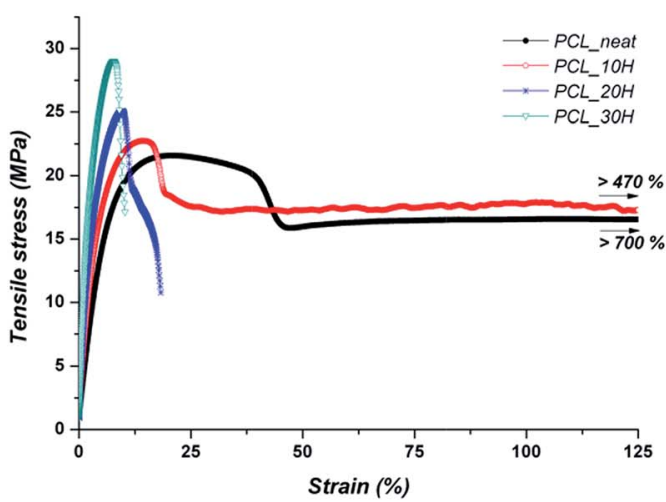

(a)

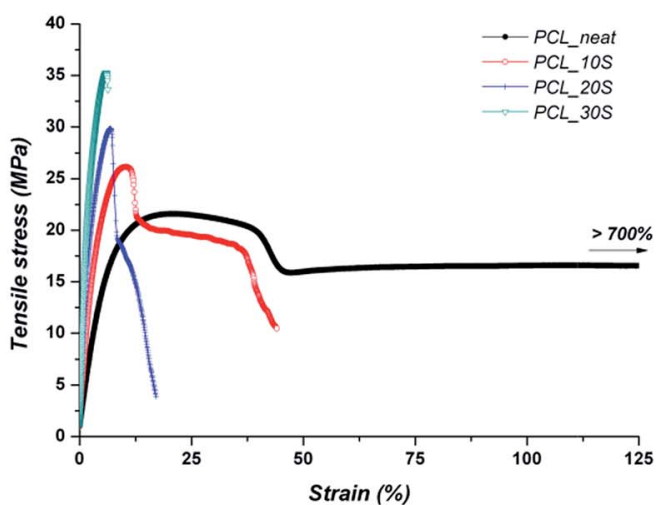

(b)

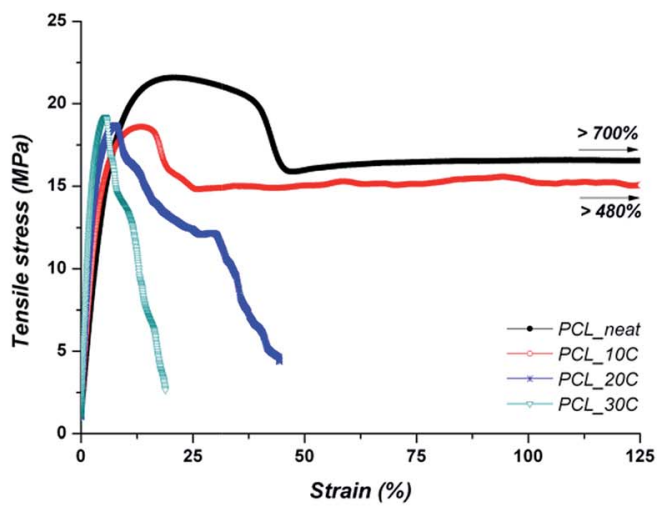

(c)

Fig. 2 Typical stress-strain curves from tensile tests for PCL-based composites as a function of increasing content of hemp (a), sisal (b) and (c) coir fibres. The behaviour of neat PCL is added as reference. 
Table 5 Mechanical properties of PCL-based composites ${ }^{a}$

\begin{tabular}{lcccc}
\hline Specimen & Tensile strength (MPa) & Young's modulus (MPa) & Strain-to-failure (\%) & Shore D hardness \\
\hline PCL_Neat & $21.13(0.40)$ & $312.99(74.40)$ & $749.24(12.28)$ & $52.95(3.17)$ \\
PCL_10S & $23.95(2.25)$ & $586.26(108.06)$ & $51.44(12.18)$ & $12.98(5.80)$ \\
PCL_20S & $26.76(2.57)$ & $962.85(123.17)$ & $6.86(1.83)$ & $55.50(2.38)$ \\
PCL_30S & $33.85(2.61)$ & $1496.33(220.48)$ & $489.34(74.17)$ & $57.70(4.21)$ \\
PCL_10H & $22.03(3.16)$ & $440.21(49.46)$ & $27.61(11.81)$ & $48.74(5.28)$ \\
PCL_20H & $24.95(0.75)$ & $589.10(94.14)$ & $9.05(1.40)$ & $50.03(2.28)$ \\
PCL_30H & $29.55(2.06)$ & $1002.56(131.09)$ & $499.84(67.12)$ & $56.61(3.81)$ \\
PCL_10C & $18.77(0.76)$ & $427.72(72.60)$ & $38.02(12.95)$ & $55.17(2.22)$ \\
PCL_20C & $19.03(0.47)$ & $558.32(54.56)$ & $208.63(51.23)$ & $56.52(2.74)$ \\
PCL_30C & $19.88(0.96)$ & $691.18(50.38)$ & $664.44(39.62)$ & $57.24(3.13)$ \\
Orfit@ & $13.02(0.39)$ & $486.29(82.45)$ & & $57.76(2.17)$ \\
Rolyan® & $19.46(0.90)$ & $565.65(40.68)$ & &
\end{tabular}

Deviations from Weibull distribution are mostly confined to the weakest fibres and can be related to the damage done to the fibres in the specimen preparation process. The Weibull moduli obtained in the present study did not exhibit a clear dependence on the gauge length for all the natural fibres investigated. These results are supported by other studies on both natural fibres and synthetic ones. ${ }^{9,11,21,24,37-39}$ Values of 2.09-4.21 are obtained for Weibull modulus and agree with typical values found in literature. Usually natural fibres are reported to show lower Weibull moduli compared to brittle man-made fibres, even though values around $3-5^{37,40}$ have been found for glass fibres and in the range 4.6-10.5 for Nextel fibres. ${ }^{41}$ The typical small values found in the present study imply that both coefficient of variation and the magnitude of the dimension effect are quite high for the strength of hemp, coir and sisal fibres. Weibull characteristic strength $\left(\chi_{0}\right)$ corresponds to a failure probability of $63.2 \%$ and is found to decrease as the gauge length increases, as shown in Table 4 . This is the confirmation of dimension effect on the strength of natural fibres. The difference in mechanical properties of the tested fibres can be linked to their function in nature. The tensile strength is mainly provided by the cellulose content and the microfibrillar angle is proportional to the strain to failure. The Young's modulus is proportional to the cellulose content and inversely proportional to the microfibrillar angle. Coir fibres in nature have the prevalent function of absorbing energy thus preventing the nut from breaking when it falls out of the tree. Coir fibres have a low cellulose content $(43 \%)$ and a large microfibrillar angle $\left(\sim 45^{\circ}\right)^{42}$ that make these fibres have a low strength, a low modulus and a high strain to failure. On the other hand, hemp and sisal fibres have a supporting function in the respective plants and, as a consequence, these fibres show higher cellulose contents (60$75 \mathrm{wt} \%$ ) and lower microfibrillar angles, 6.2 and $20.0^{\circ}$ for hemp and sisal fibres, respectively. ${ }^{42}$ This explains the higher Young's modulus exhibited by hemp fibres compared to sisal fibres, even though the strength values are very similar for both fibres. A possible explanation could be related to the fact that in contrast to the stiffness, the strength does not depend strongly on the cellulose content and spiral angle and it is largely influenced by the presence of defects that can be introduced during the extraction process.

\section{Mechanical characterization of natural fibre composites}

Typical stress-strain curves obtained from tensile tests for PCL-based composites are reported in Fig. 2 to show the effect of different natural fibre amount on the mechanical behaviour of the composites, while Table 5 summarizes the mechanical properties of all manufactured materials. In particular, PCL displays the typical cold drawing behaviour with the formation of a neck, which appears in correspondence to the yielding stress.

The formation of the neck is followed by a plastic flow occurring with almost constant stress up to the point where the alignment of the macromolecules causes a further increase of the stress versus strain up to rupture of the material. On the contrary, highly filled composites show a completely different behaviour. Cold drawing is absent in all sisal reinforced PCL composites and also for contents higher than $10 \mathrm{wt} \%$ in the case of hemp and coir. This is due to the high concentration of fibres (>10 wt\%). In this case, a yield point is still present, but the presence of fibres prevents macromolecular orientations, typical of the cold-drawing phenomenon. As a general comment, the results of tensile testing highlight that the addition of natural fibres is responsible for a significant increase in both tensile strength and Young's modulus of the composites compared to the neat matrix (Table 5), as found by other researchers for composites reinforced with the same natural fibres. ${ }^{\mathbf{4} 43-48}$ The exception is represented by coir fibres that did not allow the composites to attain strength values higher than those of the PCL matrix, irrespective of the fibre content. An almost constant value for tensile strength was found with increasing fibre content, which is undoubtedly comparable to the one of commercial materials (13.02 MPa for Orfit ${ }^{\circ}$ and 19.46 MPa for Rolyan ${ }^{\circledR}$ ) anyway. The best mechanical properties were found for composites reinforced with sisal fibres at a content of $30 \mathrm{wt} \%$, with maximum values of tensile strength and Young's modulus equal to $33.85 \mathrm{MPa}$ and $1496.33 \mathrm{MPa}$, respectively. The presence of natural fibres involved however a decrease in the elongation at break of the composites compared to both the neat matrix 


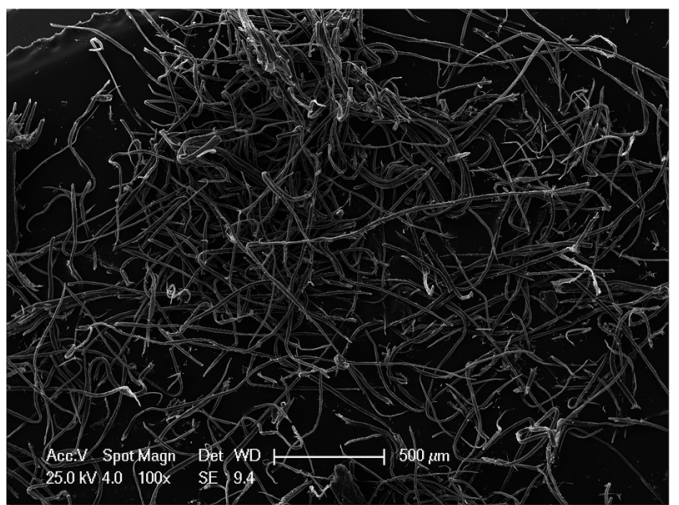

(a)

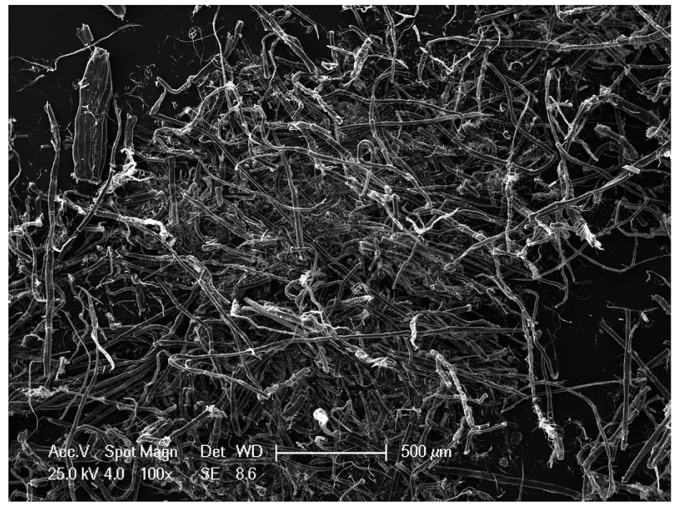

(c)

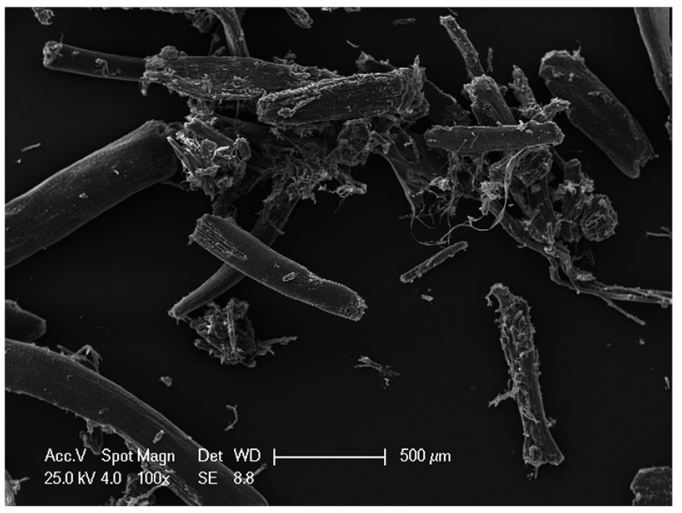

(e)

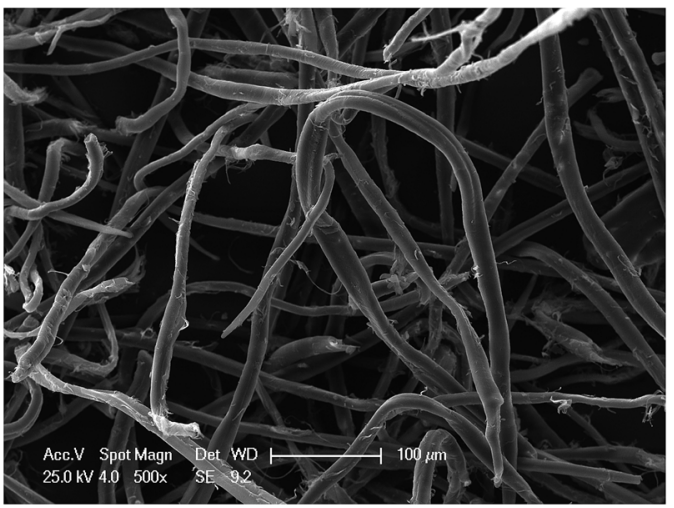

(b)

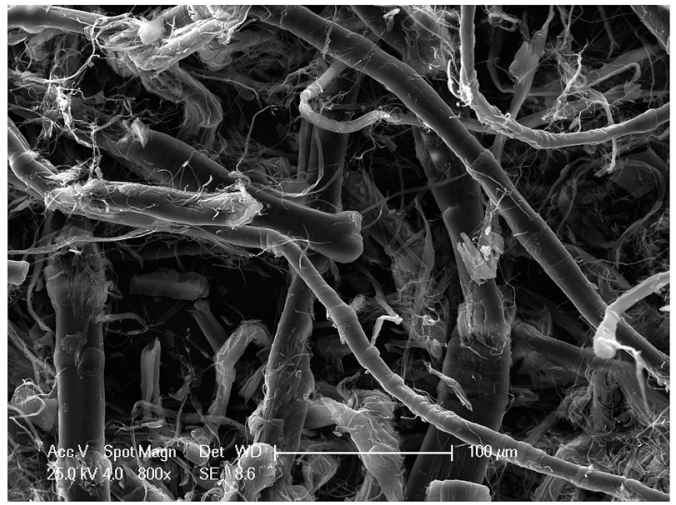

(d)

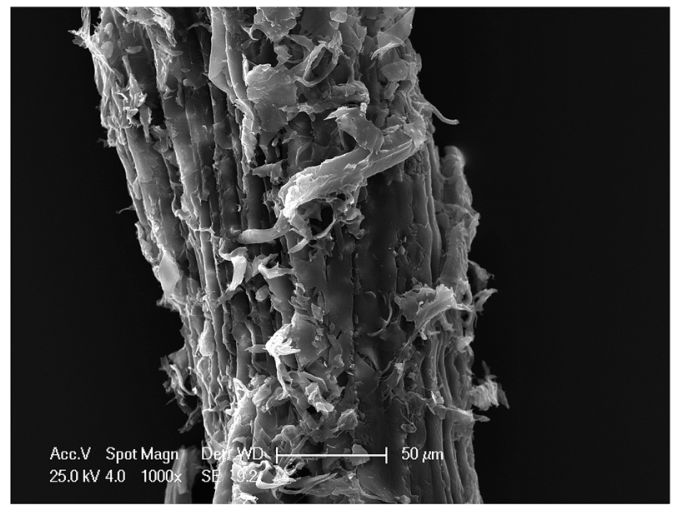

(f)

Fig. 3 SEM micrographs of extracted $(a-b)$ sisal, $(c-d)$ hemp and (e-f) coir fibres.

and the commercial materials, highlighting the following rank in descending order: neat PCL $>$ coir $>$ hemp $>$ sisal passing from values higher than $700 \%$ to a minimum of $6.86 \%$ for composites with $30 \mathrm{wt} \%$ of sisal fibres. Hardness of composite materials was less affected by the addition of natural fibres exhibiting values in the range of 54-58, which are similar to the ones of commercial materials ( 54.76 for Orfit $\circledast$ and 57.57 for Rolyan ${ }^{\circledR}$ ) (Table 5). The tested biocomposites clearly showed comparable or better characteristic values than the commercially available materials. Besides the typical increase in stiffness $(>60 \%)$, a significant increase in strength $(>40 \%)$ can be observed for sisal fibre reinforced composites. The increase in modulus is typical of composite materials based on thermoplastic matrices, where the stiffness of fibres considerably hinders the mobility of polymeric macromolecules that is responsible for plastic deformation..$^{47,49}$ The variety of natural fibres has a fundamental influence on tensile strength and Young's modulus. Within the fibres investigated, sisal seems to achieve the highest improvements. The obvious reinforcing effect is caused by the fibre performance. As previously mentioned, the fibre properties differ depending on the fibre geometry and, moreover, due to the varying chemical composition of natural fibres (e.g. cellulose, hemicellulose, lignin, pectin, etc. contents), the alignment of cellulosic chains and diverse structural defects along the fibre length. Coir fibres exhibit the lowest mechanical values, being more ductile 


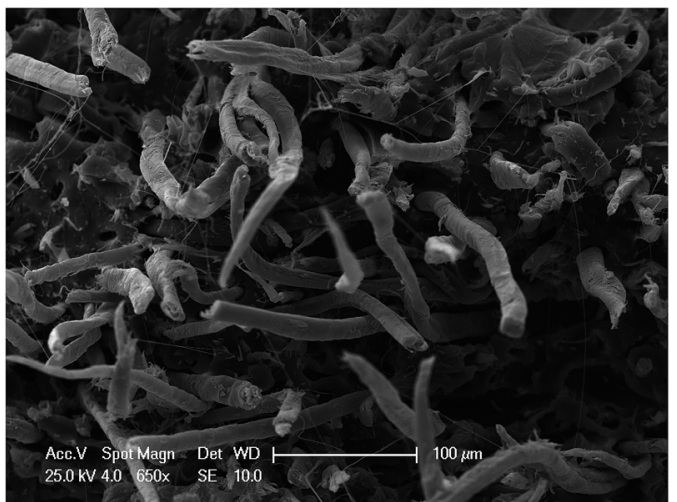

(a)

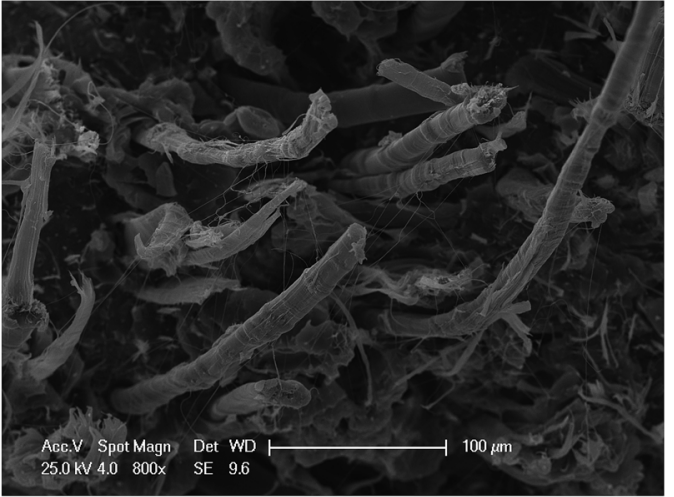

(c)

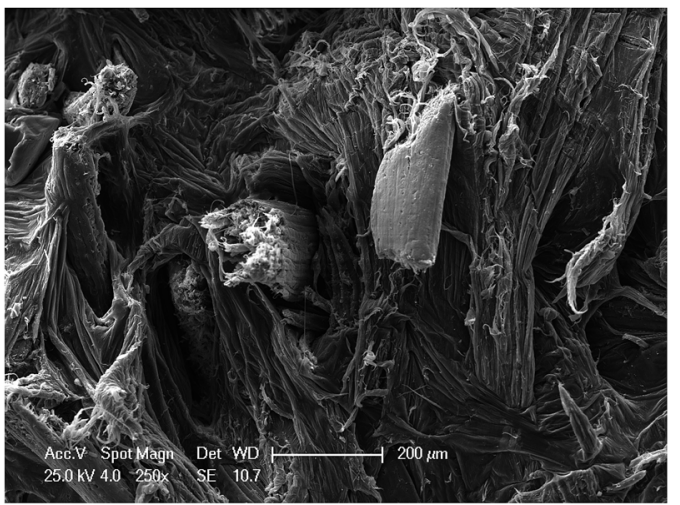

(e)

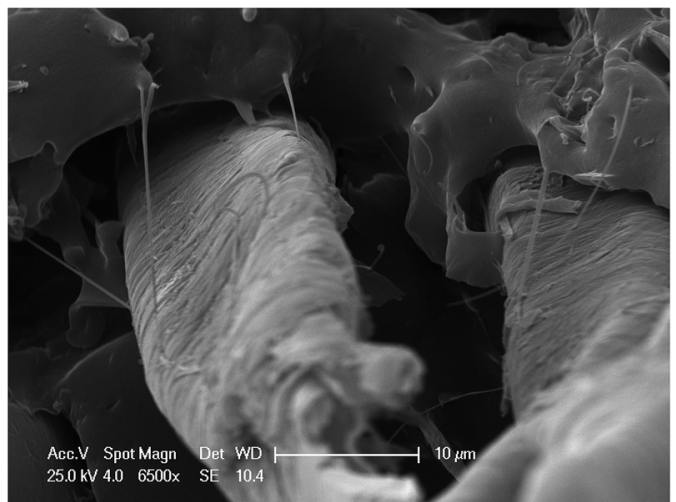

(b)

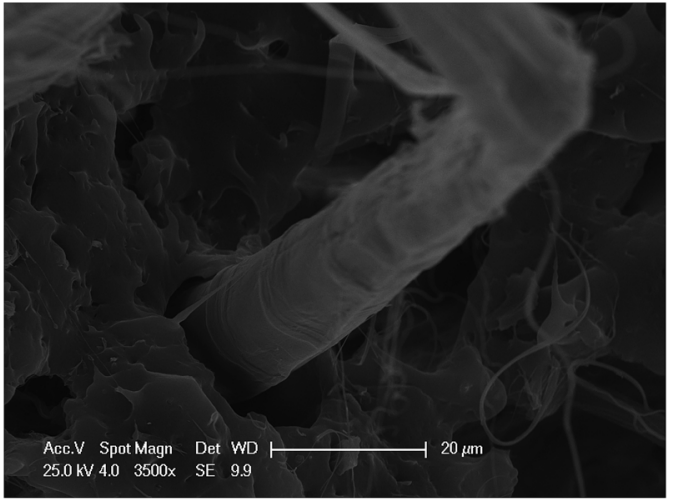

(d)

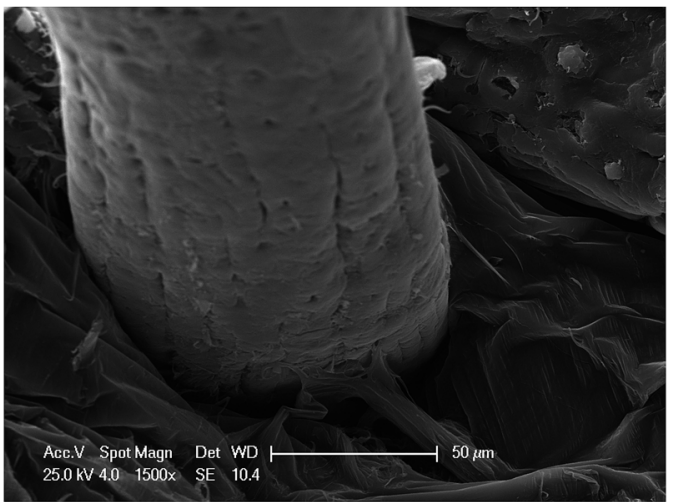

(f)

Fig. 4 SEM micrographs of the fracture surface of PCL-based composites reinforced with 30 wt\% of $(a-b)$ sisal, (c-d) hemp and (e-f) coir fibres.

than sisal and hemp ones, which show a brittle behaviour, resulting in composites with lower elongation at break. Other fundamental parameters controlling the stiffness and, to a greater extent, the tensile strength of composites, are the fibre/ matrix adhesion and the fibre aspect ratio (length/diameter). In this regard, sisal and hemp fibres are expected to exhibit a slightly better interfacial adhesion due to a rougher surface morphology that allows for a stronger mechanical interlocking effect with the matrix. This better interface is not comparable with the one achievable through the use of compatibilizing agents. In addition, hemp and sisal fibres are subject to fibrillation during the compounding and processing steps more extensively than coir fibres, with the highest tendency shown by sisal fibres. To confirm this statement, composites were dissolved in chloroform at room temperature and the fibres were investigated through scanning electron microscopy (Fig. 3). From the micrographs, a marked decrease in fibre diameter can be noted. In particular, diameters (measured on 60 fibres for each type) were in the range of $15.61 \pm 4.37 \mu \mathrm{m}$, $24.20 \pm 17.34 \mu \mathrm{m}$ and $168.45 \pm 69.59 \mu \mathrm{m}$ for sisal, hemp and coir fibres, respectively. In the present study it was not possible to accurately measure the length of the fibres, as they appeared to be highly entangled and curly. It has been reported that diameter can be much more affected than length by the processing conditions, ${ }^{50}$ so it is reasonable to assume an increase in fibre aspect ratio. ${ }^{51}$ 

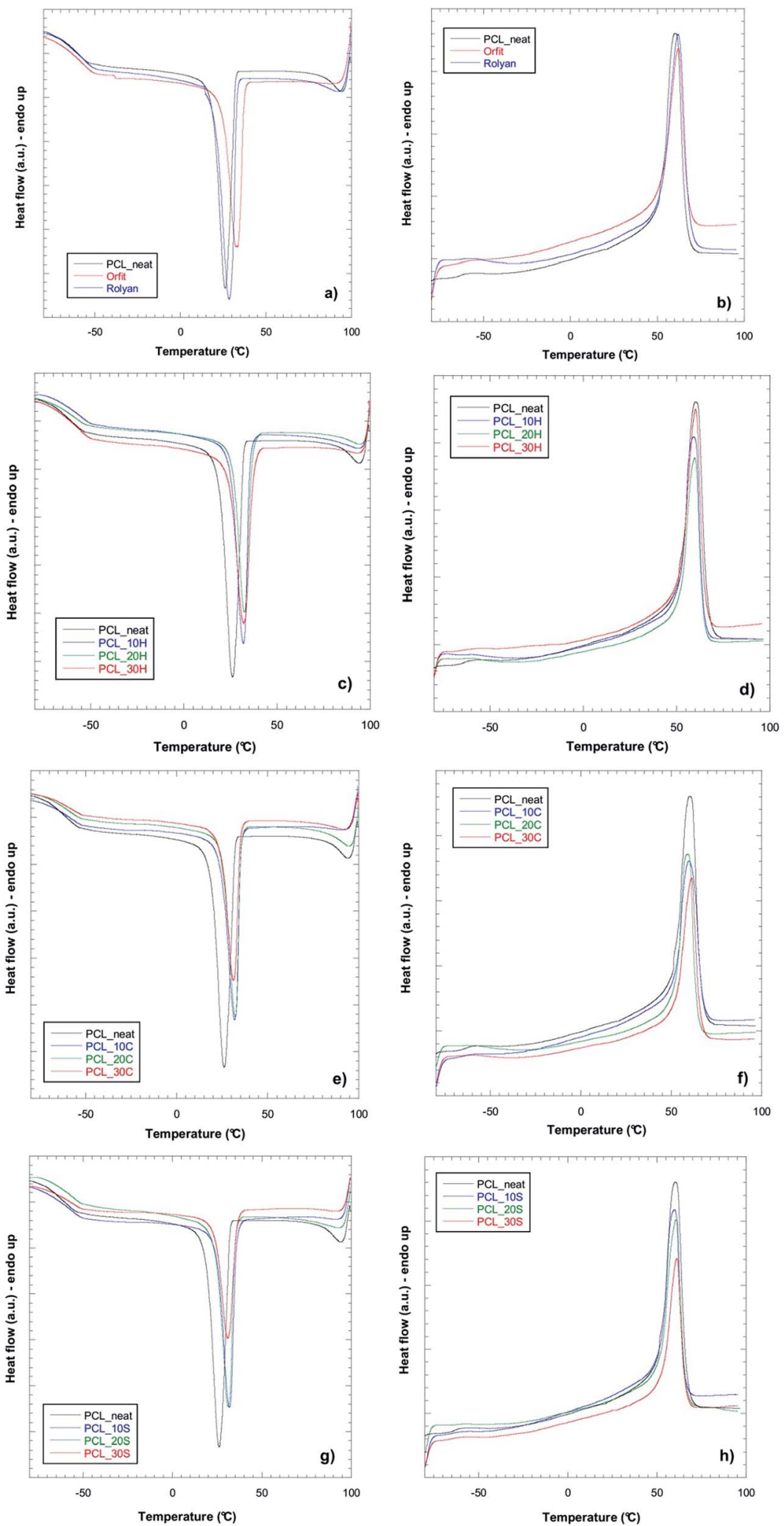

Fig. 5 DSC thermograms for PCL-based composites for the cooling step (left column) and $2^{\text {nd }}$ heating step (right column): (a-b) neat matrices; (c-d) PCL based composites with hemp fibres; (e-f) PCL based composites with coir fibres; ( $g-h)$ PCL based composites with sisal fibres.

It is clear that with an increasing aspect ratio, the composite strength increases as well, as the participated fibre surface is larger hence the stress is divided by a larger area. As a result, higher amounts of stress can be transferred without fracture. In this regard, the best results are provided by sisal and hemp fibres, thus confirming the high mechanical properties 
observed for such composites, even taking into account the absence of fibre surface treatments or matrix modifications to improve the interfacial adhesion. The limited strength of interfacial adhesion for these composites can be inferred from the SEM micrographs of the fracture surfaces shown in Fig. 4, which provide clear evidence of fibre pull-out, debonding and differences in the aspect ratio of the reinforcing fibres.

\section{Thermal characterization of natural fibre composites}

The thermal characterization of PCL-based composites was carried out using DSC. From the thermograms (Fig. 5a-h), the melting temperature $\left(T_{\mathrm{m}}\right)$, associated heat of melting $\left(\Delta H_{\mathrm{m}}\right)$, degree of crystallinity $\left(X_{\mathrm{c}}\right)$ and crystallization temperature $\left(T_{\mathrm{c}}\right)$ were obtained. The resulting experimental data are summarized in Table 6. For all composites, the crystallization temperature is slightly increased (around $5{ }^{\circ} \mathrm{C}$ ) compared to the neat matrix, which can be translated as a difficulty for the PCL chains to rearrange themselves in presence of fibres. The incorporation of the natural fibres at the different weight level into PCL induced a change in the crystallization temperature with respect of neat PCL, indicating the occurrence of a nucleating effect of fibres on the crystal growth of PCL. The comparison of the $T_{\mathrm{c}}$ temperature in composites with the same weight amount of fibres confirmed that no substantial differences can be found for the molecular mobility of the PCL in case of fibres without any surface treatment. ${ }^{52,53}$

For all composites, $T_{\mathrm{m}}$ remained almost constant for each type of fibre irrespective of fibre content as observed, for example, for flax fibre reinforced PCL composites. ${ }^{\mathbf{5 4 5 5}}$ The reduced decrease in melting parameters (temperature and enthalpy) can be seen as a restriction of the periodic arrangements of PCL chains into its lattice, leading to some loss in the polymer crystallinity in biocomposites with respect to neat PCL. ${ }^{56,57}$ As the concentration of the fibres was increased, the relative weight percent of the PCL in the compound was decreased, leading to a lower endothermic area $\left(\mathrm{J} \mathrm{g}^{-1}\right)$. Moreover, the occurrence of double melting peaks or different shape of main melting peak was not evidenced. On the contrary, the degree of crystallinity of PCL is markedly influenced by the

Table 6 Thermal characteristics of PCL-based composites obtained from DSC analysis ${ }^{a}$

\begin{tabular}{lllll}
\hline Specimen & $T_{\mathrm{c}}\left({ }^{\circ} \mathrm{C}\right)$ & $\Delta H_{\mathrm{m}}\left(\mathrm{J} \mathrm{g}^{-1}\right)$ & $T_{\mathrm{m}}\left({ }^{\circ} \mathrm{C}\right)$ & $X_{\mathrm{c}}(\%)$ \\
\hline PCL_Neat & $26.4 \pm 0.3$ & $86.5 \pm 2.2$ & $60.0 \pm 0.2$ & $62.0 \pm 1.6$ \\
PCL_10S & $31.5 \pm 0.6$ & $86.3 \pm 0.5$ & $60.0 \pm 0.3$ & $55.6 \pm 0.3$ \\
PCL_20S & $31.3 \pm 0.2$ & $64.8 \pm 3.2$ & $60.5 \pm 0.4$ & $37.1 \pm 1.8$ \\
PCL_30S & $31.0 \pm 0.3$ & $61.1 \pm 0.8$ & $57.8 \pm 4.4$ & $30.7 \pm 0.4$ \\
PCL_10H & $31.0 \pm 1.1$ & $96.6 \pm 6.3$ & $60.6 \pm 2.3$ & $62.3 \pm 4.1$ \\
PCL_20H & $32.1 \pm 0.5$ & $65.9 \pm 4.2$ & $60.2 \pm 0.7$ & $37.8 \pm 2.4$ \\
PCL_30H & $32.1 \pm 1.2$ & $58.2 \pm 1.6$ & $59.9 \pm 1.5$ & $29.2 \pm 0.8$ \\
PCL_10C & $32.1 \pm 0.4$ & $64.1 \pm 6.4$ & $60.2 \pm 0.8$ & $41.4 \pm 4.1$ \\
PCL_20C & $32.3 \pm 0.2$ & $63.8 \pm 3.6$ & $59.3 \pm 0.6$ & $36.6 \pm 2.1$ \\
PCL_30C & $31.7 \pm 0.6$ & $60.4 \pm 1.7$ & $58.2 \pm 2.4$ & $30.3 \pm 0.8$ \\
Orfit® & $31.4 \pm 1.7$ & $59.0 \pm 4.5$ & $61.6 \pm 0.7$ & $42.3 \pm 3.2$ \\
Rolyan® & $28.3 \pm 0.3$ & $78.9 \pm 1.5$ & $62.1 \pm 0.2$ & $56.6 \pm 1.0$
\end{tabular}

${ }^{a}$ Note: values given in parentheses are standard deviations. presence of natural fibres. In particular, all types of natural fibres seem to restrict the periodic arrangements of PCL chains into its lattice, leading to a decrease in crystallinity of neat PCL with the increase in fibre content.

In polymer/natural fibre composites, the heterogeneous nucleation on the filler's surface is the main mechanism responsible for the crystallization behaviour of the matrix. In such cases transcrystalline layers can form but, depending on the filler nature and content, transcrystallization may be restricted by filler-filler contacts and agglomeration that reduces the exposed surface area of the filler. ${ }^{58,59}$ Transcrystallization can reduce the final degree of crystallinity of the matrix due to the reduced mobility of the polymer chains as a consequence of the quick formation of high density nuclei on the filler surface. In this case, the higher surface area of the fibres (due to reduction of fibre's diameter) and the absence of marked fibres' agglomeration do not seem to affect the transcrystallization behaviour, thus still allowing a good nucleating ability even at higher filler contents with related reduction in overall crystallinity of the matrix. This behaviour was observed in other studies on PCL reinforced with natural fibres. ${ }^{49,55,56,60,61}$

\section{Conclusions}

The effect of lignocellulosic fibre type and content on the thermal and mechanical properties of polycaprolactone based composites was addressed. The results confirmed that the addition of natural fibres to a biodegradable matrix (PCL) allows for significant improvement of the mechanical behaviour of the resulting composites (in terms of strength and stiffness) compared to commercially available materials used in orthotics, thus proving their potential application in the fabrication of orthotic devices. The best performance was obtained for composites reinforced with $30 \mathrm{wt} \%$ of sisal fibres due to a balance of fibre properties and favourable aspect ratio after compounding and processing steps. Differences in reinforcing efficiency among bast, leaf and fruitextracted fibres were highlighted and correlated with the fibre mechanical properties and microstructure of the ensuing composites. As regards the thermal behaviour, all the fibres were found to affect the crystallization behaviour of the neat matrix causing a degree of the overall degree of crystallinity of polycaprolactone. It seems necessary nevertheless both to demonstrate the effectiveness of biocomposites-based orthoses through a proper clinical experimentation and to investigate which is the most cost-effective manufacturing process.

\section{Acknowledgements}

Authors acknowledge Perstorp and Gruppo Fibranova S.r.l. for supplying polycaprolactone and hemp fibres, respectively.

\section{Notes and references}

1 S. Fatone, in Wiley Encyclopedia of Biomedical Engineering, ed. M. Akay, John Wiley \& Sons Inc, Hoboken, NJ, 2006, pp. 2667-2681.

2 E. E. Fess, J. Hand Ther., 2002, 15, 97-132. 
3 E. Taylor, J. Hanna and H. J. C. Belcher, Current Orthopaedics, 2003, 17, 465-474.

4 O. Faruk, A. K. Bledzki, H.-P. Fink and M. Sain, Prog. Polym. Sci., 2012, 37, 1552-1596.

5 M. Fuqua, S. Huo and C. Ulven, Polym. Rev., 2012, 52, 259-320.

6 F. P. La Mantia and M. Morreale, Composites, Part A, 2011, 42, 579-588.

7 E. Bodros and C. Baley, Mater. Lett., 2008, 62, 2143-2145.

8 Z. P. Xia, J. Y. Yu, L. D. Cheng, L. F. Liu and W. M. Wang, Composites, Part A, 2009, 40, 54-59.

9 J. Andersons, E. Sparnins, R. Joffe and L. Wallstrom, Compos. Sci. Technol., 2005, 65, 693-702.

10 I. M. De Rosa, J. M. Kenny, D. Puglia, C. Santulli and F. Sarasini, J. Reinf. Plast. Compos., 2010, 29, 3450-3454.

11 A. Bezazi, A. Belaadi, M. Bourchak, F. Scarpa and K. Boba, Composites, Part B, 2014, 66, 194-203.

12 C. G. Pitt, F. I. Chasalow, Y. M. Hibionada, D. M. Klimas and A. Schindler, J. Appl. Polym. Sci., 1981, 26, 3779-3787.

13 Y. Li, Y.-W. Mai and L. Ye, Compos. Sci. Technol., 2000, 60, 2037-2055.

14 M. A. Fuqua, S. Huo and C. A. Ulven, Polym. Rev., 2012, 52, 259-320.

15 F. A. Silva, N. Chawla and R. D. Toledo Filho, Compos. Sci. Technol., 2008, 68, 3438-3443.

16 I. M. De Rosa, J. M. Kenny, D. Puglia, C. Santulli and F. Sarasini, Compos. Sci. Technol., 2010, 70, 116-122.

17 A. Bourmaud and C. Baley, Polym. Degrad. Stab., 2009, 94, 297-305.

18 C. Baley, Composites, Part A, 2002, 33, 939-948.

19 J. Biagiotti, S. Fiori, L. Torre, M. A. Lòpez-Manchado and J. M. Kenny, Polym. Compos., 2004, 25, 26-36.

20 K. Charlet, C. Baley, C. Morvan, J. P. Jernot, M. Gomina and J. Bréard, Composites, Part A, 2007, 38, 1912-1921.

21 N. Defoirdt, S. Biswas, L. De Vriese, L. Q. N. Tran, J. Van Acker, Q. Ahsan, L. Gorbatikh, A. Van Vuure and I. Verpoest, Composites, Part A, 2010, 41, 588-595.

22 F. Tomczak, T. H. D. Sydenstricker and K. G. Satyanarayana, Composites, Part A, 2007, 38, 1710-1721.

23 H. Bos, M. Van Den Oever and O. Peters, J. Mater. Sci., 2002, 37, 1683-1692.

24 T.-T.-L. Doan, S.-L. Gao and E. Mäder, Compos. Sci. Technol., 2006, 66, 952-963.

25 G. G. Silva, D. A. De Souza, J. C. Machado and D. J. Hourston, J. Appl. Polym. Sci., 2000, 76, 1197-1206.

26 J. E. van Dam, M. J. van den Oever, W. Teunissen, E. R. Keijsers and A. G. Peralta, Ind. Crops Prod., 2004, 19, 207-216.

27 M. M. Rahman and M. A. Khan, Compos. Sci. Technol., 2007, 67, 2369-2376.

28 V. Placet, Composites, Part A, 2009, 40, 1111-1118.

29 G. W. Beckermann and K. L. Pickering, Composites, Part A, 2008, 39, 979-988.

30 J.-M. Park, S. T. Quang, B.-S. Hwang and K. L. DeVries, Compos. Sci. Technol., 2006, 66, 2686-2699.

31 A. Shahzad, Adv. Mater. Sci. Eng., 2013, 2013, 1-9.

32 S. J. Eichhorn and R. J. Young, Compos. Sci. Technol., 2004, 64, 767-772.
33 M. A. Sawpan, K. L. Pickering and A. Fernyhough, Composites, Part A, 2011, 42, 888-895.

34 A. Belaadi, A. Bezazi, M. Bourchak and F. Scarpa, Mater. Des., 2013, 46, 76-83.

35 A. V. Ratna Prasad and K. Mohana Rao, Mater. Des., 2011, 32, 4658-4663.

36 J. T. Kim and A. N. Netravali, Composites, Part A, 2010, 41, 1245-1252.

37 J. Andersons, R. Joffe, M. Hojo and S. Ochiai, Compos. Sci. Technol., 2002, 62, 131-145.

38 F. Wang, J. Shao and X. Li, Polym. Compos., 2014, DOI: 10.1002/pc.23173.

39 C. V. Sia, Y. Nakai, D. Shiozawa and H. Ohtani, Open J. Compos. Mater., 2014, 04, 72-77.

40 S. Feih, A. Thraner and H. Lilholt, J. Mater. Sci., 2005, 40, 1615-1623.

41 N. Chawla, M. Kerr and K. K. Chawla, J. Am. Ceram. Soc., 2004, 88, 101-108.

42 A. Bledzki and J. Gassan, Prog. Polym. Sci., 1999, 24, 221-274.

43 A. Bourmaud and C. Baley, Polym. Degrad. Stab., 2007, 92, 1034-1045.

44 K. L. Fung, X. S. Xing, R. K. Y. Li, S. C. Tjong and Y.-W. Mai, Compos. Sci. Technol., 2003, 63, 1255-1258.

45 A. Keller, Compos. Sci. Technol., 2003, 63, 1307-1316.

46 M. M. Haque, M. Hasan, M. S. Islam and M. E. Ali, Bioresour. Technol., 2009, 100, 4903-4906.

$47 \mathrm{H}$. Ku, H. Wang, N. Pattarachaiyakoop and M. Trada, Composites, Part B, 2011, 42, 856-873.

48 C. Y. Lai, S. M. Sapuan, M. Ahmad, N. Yahya and K. Z. H. M. Dahlan, Polym.-Plast. Technol. Eng., 2005, 44, 619-632.

49 L. Ludueña, A. Vázquez and V. Alvarez, Carbohydr. Polym., 2012, 87, 411-421.

50 A. K. Bledzki and A. Jaszkiewicz, Compos. Sci. Technol., 2010, 70, 1687-1696.

51 S. Iannace, R. Ali and L. Nicolais, J. Appl. Polym. Sci., 2001, 79, 1084-1091.

52 M. M.-U. Haque, M. E. Errico, G. Gentile, M. Avella and M. Pracella, Macromol. Mater. Eng., 2012, 297, 985-993.

53 G. Siqueira, J. Bras and A. Dufresne, Biomacromolecules, 2009, 10, 425-432.

54 A. Arbelaiz, B. Fernández, A. Valea and I. Mondragon, Carbohydr. Polym., 2006, 64, 224-232.

55 K. Leluk and M. Kozlowski, Fibers Polym., 2014, 15, 108-116. 56 Q. Zhao, J. Tao, R. C. M. Yam, A. C. K. Mok, R. K. Y. Li and C. Song, Polym. Degrad. Stab., 2008, 93, 1571-1576.

57 Y. Wang, M. A. Rodriguez-Perez, R. L. Reis and J. F. Mano, Macromol. Mater. Eng., 2005, 290, 792-801.

58 H. Quan, Z.-M. Li, M.-B. Yang and R. Huang, Compos. Sci. Technol., 2005, 65, 999-1021.

59 S.-J. Son, Y.-M. Lee and S.-S. Im, J. Mater. Sci., 2000, 35, 57675778.

60 C.-S. Wu, J. Appl. Polym. Sci., 2010, 115, 948-956.

61 A. Campos, J. M. Marconcini, S. H. Imam, A. Klamczynski, W. Ortis, D. Wood, T. Williams, S. Martins-Franchetti and L. Mattoso, J. Reinf. Plast. Compos., 2012, 31, 573-581. 